\title{
Betulinic acid treatment promotes apoptosis in hepatoblastoma cells
}

\author{
M. EICHENMÜLLER, D. VON SCHWEINITZ and R. KAPPLER \\ Department of Pediatric Surgery, Dr von Hauner Children's Hospital, \\ Ludwig-Maximilians-University Munich, 80337 Munich, Germany
}

Received April 3, 2009; Accepted May 21, 2009

DOI: 10.3892/ijo_00000402

\begin{abstract}
Hepatoblastoma (HB) represents the most common malignant liver tumor in children with a dismal prognosis for patients with advanced disease. This study provides evidence that the naturally occurring pentacyclic triterpenoid betulinic acid (BA) is highly effective against $\mathrm{HB}$. We demonstrate that BA has a strong cytotoxic effect on HB cells in a dosedependent manner by impinging on cell viability and causing massive induction of programmed cell death. Apoptotic features including morphological changes, membrane asymmetry and proteolytic cleavage of caspase 3 and poly(ADP-ribose) polymerase were frequently found in BAtreated HB cells, which is suggestive of the mitochondrial intrinsic apoptotic pathway. In contrast, the hepatocellular carcinoma (HCC) cell line HepG2 was resistant to BA treatment. This insensitivity was dependent on the high expression of survival factors, such as Survivin and BCL2. Interestingly, BA treatment led to a significant decrease in expression of the hedgehog target genes GLI1, PTCHI and IGF2 in HepT3 cells. In conclusion, we demonstrate that BA is capable of inducing apoptosis in HB cells and thereby might be a hopeful new strategy for treating HB, especially those with an activated hedgehog signaling pathway.
\end{abstract}

\section{Introduction}

Hepatoblastoma (HB) is the most common hepatic tumor in childhood with an incidence of $\sim 1$ per million children below 15 years of age (1). This tumor especially affects young children between 6 months and 3 years of age with an overall median age of 18 months at diagnosis $(2,3)$. Histologically, there are two major subtypes of HB; epithelial and mixed epithelial/mesenchymal. The majority of HB are epithelial

Correspondence to: Dr Roland Kappler, Department of Pediatric Surgery, Dr von Hauner Children's Hospital, Ludwig-MaximiliansUniversity Munich, 4 Lindwurmstr., D-80337 Munich, Germany

E-mail: roland.kappler@med.uni-muenchen.de

Key words: betulinic acid, hepatoblastoma, apoptosis, hedgehog tumors showing cells with fetal and/or embryonal hepatic differentiation, whereas mixed HB also contain mesenchymal elements such as immature fibrous tissue or spindle cells and osteoid (3). Although HB treatment has dramatically improved during the past 20 years by combining chemotherapy regimens with surgery, the fatal outcome of high-risk patients with advanced or recurrent $\mathrm{HB}$ makes new treatment strategies essential $(4,5)$.

On the molecular level, a high proportion of $\mathrm{HB}$ exhibits loss of heterozygosity and/or imprinting defects at the chromosomal band $11 \mathrm{p} 15.5$, which harbors the insulin-like growth factor-II (IGF2) gene (6-8). It is commonly accepted that overexpression of IGF2 is one of the driving forces in the development and progression of HB (9). Several lines of evidence indicate that IGF2 promotes cell survival and inhibits apoptosis via the phosphatidylinositol 3-kinase (PI3K)/AKT signaling pathway, which is frequently altered in cancer $(10,11)$. The serine/threonine kinase AKT is known to elicit its effects through phosphorylation and inactivation of proapoptotic factors and it has been suggested that this may afford tumor cells a survival advantage (12). Therefore, identifying new drugs that inhibit PI3K/AKT signaling and induce apoptosis might be a promising strategy to develop more effective therapies for HB in the future.

The plant-derived betulinic acid (BA) has been reported to exhibit anti-tumoral activity in a variety of human cancers such as melanoma (13) and tumors of the lung, colon, prostate and ovary (14), whereas BA showed minimal toxicity against normal cells (15). BA is known to induce apoptosis by the intrinsic apoptosis pathway followed by the activation of specific caspases (16-18). Moreover, BA showed a beneficial effect in drug-resistant tumor cell lines (19). Since other embryonal tumors such as medulloblastoma and neuroblastoma have been described to display PI3K/AKTassociated features of cell survival $(20,21)$, but could be successfully treated with BA $(22,23)$, we wondered whether BA has also a cytotoxic effect on HB.

Here, we report that BA treatment leads to a dosedependent growth inhibition and induction of apoptosis in HB cells. In contrast, the hepatocellular carcinoma (HCC) cell line HepG2 displayed no evidence for apoptosis, which could be explained by an increased expression of survival genes such as Survivin and BCL2 in this cell line. Furthermore, we demonstrated that the expression of the hedgehog target genes GLII, PTCH1 and IGF2 was significantly decreased in 
hedgehog-activated HB cells upon BA treatment. These findings suggest that BA is able to inhibit tumor growth of $\mathrm{HB}$ in vitro and that it may be a hopeful new strategy for the treatment of this malignant liver tumor.

\section{Materials and methods}

Tumor cell lines. The three human HB cell lines HUH6 (Japanese Collection of Research Bioresources, Osaka, Japan), HepT1 (24) and HepT3 (6), as well as the HCC cell line HepG2 (ATCC, Manassas, VA, USA) were used for all experiments. Cell lines were maintained as the suppliers recommended. Human fibroblasts were grown in DMEM supplemented with $10 \%$ FCS and $1 \%$ penicillin/streptomycin.

Western blot analysis. Protein $(20 \mu \mathrm{g})$ was isolated and separated on $12 \%$ SDS-PAGE under reducing conditions as described earlier (25). Proteins were then transferred to nitrocellulose membranes (GE Healthcare, Piscataway, NJ, USA). The membranes were incubated with PBS containing $0.1 \%$ Tween-20 and 5\% non-fat dry milk to block non-specific binding, then incubated with rabbit anti-human AKT, rabbit anti-human phospho-AKT (Ser473), mouse anti-human caspase 3, rabbit anti-human cleaved caspase 3, rabbit antihuman poly(ADP-ribose) polymerase or rabbit anti-human B-actin (all from Cell Signaling Technology, Danvers, MA, USA) for $1.5 \mathrm{~h}$ and thereafter for $1 \mathrm{~h}$ with the appropriate horseradish peroxidase-conjugated secondary antibody (DakoCytomation, Hamburg, Germany). Signals were visualized using the ECL chemiluminescence detection system (GE Healthcare).

Cell viability and morphology. Cell growth was assessed using the Cell Proliferation Kit I (Roche Diagnostics, Penzberg, Germany) according to the manufacturer's protocol. Cells were seeded at a density of $5 \times 10^{3}$ cells/96-well plate (Nunc, Wiesbaden, Germany) and after overnight attachment treated for $24 \mathrm{~h}$ with $0-50 \mu \mathrm{g} / \mathrm{ml}$ BA (BioSolutions, Halle, Germany) dissolved in DMSO. Cell viability was measured after addition of 3-(4,5-dimethylthiazol-2-yl)-2,5-diphenyltetrazolium bromide (MTT) labeling reagent on the GENios reader (Tecan, Männedorf, Switzerland) at a wavelength of $595 \mathrm{~nm}$. Morphological changes of incubated cells were documented with a Zeiss inverted phase-contrast microscope equipped with a Canon PowerShot G6 digital device.

Apoptosis analyses. Cells were seeded at a density of $2 \times 10^{5}$ cells/well onto chamber slides or 6-well plates (both from Nunc). After overnight attachment, cells were cultured for $48 \mathrm{~h}$ in the presence or absence of $10 \mu \mathrm{g} / \mathrm{ml} \mathrm{BA}$. For immunofluorescent staining of cleaved caspase 3 , cells were fixed in chamber slides for $20 \mathrm{~min}$ in fresh $4 \%$ paraformaldehyde at room temperature, permeabilized in $0.1 \%$ Triton $\mathrm{X}-100 / 0.1 \%$ sodium citrate, blocked in 5\% BSA and incubated overnight at $4^{\circ} \mathrm{C}$ with a polyclonal rabbit anti-human cleaved caspase 3 antibody (Cell Signaling Technology). Cells were then incubated for 30 min with FITC-conjugated sheep anti-rabbit IgG (1:320, Sigma-Aldrich, Hamburg, Germany) at room temperature. Nuclear staining was performed with Vectashield ${ }^{\circledR}$ containing 4,6-diamidino-2-pheylindole (Vector Laboratories
Inc., Burlingame, CA, USA). Cleaved caspase 3-positive cells were counted at $\mathrm{x} 200$ magnification in at least 10 microscope fields. For annexin V-based apoptosis analysis, cells were trypsinized in 6-well plates, washed with PBS and suspended in $500 \mu 1$ of calcium-containing binding buffer. Cy5-conjugated annexin V (1:100; BioVision, Mountain View, CA, USA) and $5 \mu \mathrm{M}$ calcein (Invitrogen, Carlsbad, CA, USA) were added to the cell suspension. Early apoptotic cells (annexin $\mathrm{V}$ and calcein-positive) were detected using cell fluorescence assays on a 2100 Bioanalyzer (Agilent Technologies, Santa Clara, CA, USA).

Real-time reverse transcription-PCR ( $R T-P C R)$. RNA extraction and real-time RT-PCR was performed as previously described (25). We used the following primer pairs $\left(5^{\prime}->3^{\prime}\right.$ orientation): $B C L 2$, CGCCCTGTGGATGACTGAGTAC, CAAACAGAGGCCGCATGCT; Survivin, GGACAGAGAA AGAGCCAAGAACAA, CCAGCTGCTCGATGGCAC; GLI1, AGCTACATCAACTCCGGCCA, GCTGCGGCGTT CAAGAGA; $I G F 2$, CCTCCGACCGTGCTTCC, GGTGGA CTGCTTCCAGGTGT; PTCH1, TTGATTGTGGGTGG CACAGT, GCTTGGGAGTCATTAACTGGAAC; TATA box-binding protein (TBP), GCCCGAAACGCCGAATAT, CCGTGGTTCGTGGCTCTCT. Amplification of the housekeeping gene TBP was performed to standardize the amount of sample RNA. Relative quantification of gene expression was performed using the $\Delta \Delta$ ct method as described earlier (26).

Statistical analysis. Data were expressed as means + standard deviation and statistically subjected to Student's unpaired t-test. A level of $\mathrm{P}<0.05$ was considered to be significant.

\section{Results}

Betulinic acid inhibits PI3K/AKT-mediated growth of HB cells. Several lines of evidence indicate that upregulation of $I G F 2$ is a key event in the development of HB (9). Since IGF2 is known to activate the PI3K/AKT pathway (11) we wondered whether an autocrine IGF2 regulatory circuit is also activated in HB. Therefore, we have verified the phosphorylation status of the key protein of PI3K/AKT signaling, the serine/threonine kinase AKT. Using Western blot analysis we found a strong activation of AKT in all three HB cell lines under investigation, namely HUH6, HepT1 and HepT3 (Fig. 1). Interestingly, these cell lines originate from different histological subtypes comprising epithelial and mixed HB. In contrast, the HCC cell line HepG2 exhibited only unphosphorylated AKT. This suggests that IGF2 overexpression, which is consistently found in HB tumors (9), could lead to a constitutive activation of AKT in these tumors independent of their histology. In contrast, in HCC deregulation other than activated PI3K/AKT signaling might be implicated in tumorigenesis.

Since activation of $\mathrm{PI} 3 \mathrm{~K} / \mathrm{AKT}$ signaling is known to trigger downstream responses such as cell survival and inhibition of apoptosis, which leads to the increased ability of cancer cells to survive (11), we next examined whether abrogation of these molecular mechanisms could be used to inhibit HB growth in vitro. BA displays a promising agent 


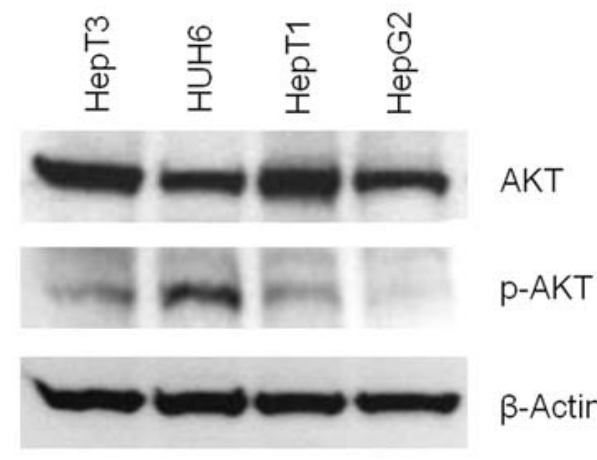

Figure 1. AKT phosphorylation in HB cells. Protein expression levels of AKT and activated phospho-AKT in the HB cell lines HepT3, HUH6 and HepT1, and the HCC cell line HepG2. Protein levels were detected by Western blot analysis using $20 \mu \mathrm{g}$ of whole cell lysate. The expression of $\beta$-actin protein served as a standard control for equal protein loading.

known to exert a strong cytotoxic effect on a variety of human cancers by inhibiting growth and inducing apoptosis (14). By applying BA concentrations $(0-50 \mu \mathrm{g} / \mathrm{ml})$ comparable to those used in previous studies $(13,17)$ we observed a dose-dependent decrease in cell viability in all tumor cell lines by means of MTT assay (Fig. 2). This effect was selective for tumor cells, since normal fibroblasts were hardly responsive to BA treatment. However, high concentrations of BA $(50 \mu \mathrm{g} / \mathrm{ml})$ had a strong cytotoxic effect and resulted in complete killing of all cell lines. The half-maximal cytotoxic concentration $\left(\mathrm{IC}_{50}\right)$ of BA at $24 \mathrm{~h}$ was $4.70 \mu \mathrm{g} / \mathrm{ml}$, $6.95 \mu \mathrm{g} / \mathrm{ml}, 2.19 \mu \mathrm{g} / \mathrm{ml}, 2.89 \mu \mathrm{g} / \mathrm{ml}$ and $23.91 \mu \mathrm{g} / \mathrm{ml}$ for HUH6, HepT1, HepT3, HepG2 and normal fibroblasts, respectively. Taken together our results clearly demonstrate that BA is highly effective against excessive growth of childhood liver tumor cells.

$B A$ selectively induces apoptosis in $H B$ cells. Since it is known that BA exerts its anti-tumorigenic effect by inducing apoptosis $(13,17,23)$, we next verified whether BA can induce apoptotic characteristics in HB cells. First, we screened HB cells after BA treatment for apoptosis-specific morphological changes, such as cell shrinkage, membrane blebbing, nuclear fragmentation and formation of apoptotic bodies. Strikingly, BA treatment resulted in a strong increase of apoptosis in the three tested HB cell lines, but not in the HCC cell line HepG2 (Fig. 3a). We then analyzed membrane integrity by annexin $\mathrm{V}$ staining in BA-treated HB cells. Consistent with the morphological changes of HB cells we found significantly elevated external appearance of phosphatidylserine in $\mathrm{HB}$ cells, whereas HCC cells showed almost no induction of membrane asymmetry (Fig. 3b). Thereafter, we examined a later stage of apoptosis characterized by proteolytic cleavage of caspase 3 by immunofluorescence. In the presence of BA cleaved caspase 3-positive cells were markedly increased only in HB cell lines (Fig. 3c). Consistently, using Western blot analysis we detected increased levels of the activated form of caspase 3 and its known downstream target poly(ADP-ribose) polymerase in the HB cell lines, which was most prominent in the $10 \mu \mathrm{g} / \mathrm{ml} \mathrm{BA}$ treatment samples (Fig. 3d). Contrarily, the HCC cells lack activated forms of both apoptosis-related proteins. Altogether, these findings

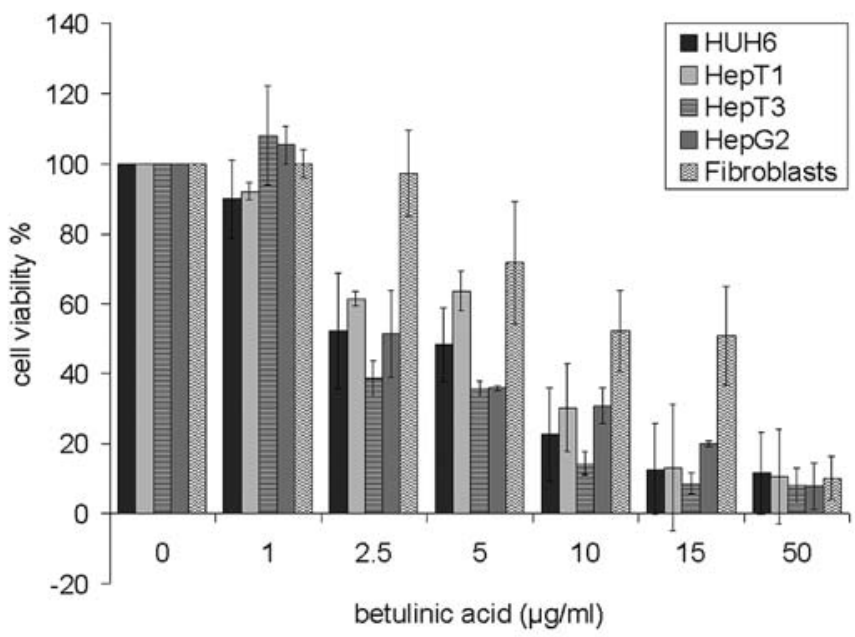

Figure 2. BA treatment causes decreased cell viability of $\mathrm{HB}$ cells. The HB cell lines HUH6, HepT1, and HepT3, the HCC cell line HepG2 and normal human fibroblasts were treated for $24 \mathrm{~h}$ with increasing BA concentrations. Cell viability was analyzed by MTT assay in three independent experiments and is depicted as the mean percentage \pm standard deviation of viable cells.

suggest that BA treatment effectively induces apoptosis in HB cells.

However, the reason for the inability of the HCC cells to undergo apoptosis upon BA treatment has prompted us to investigate the molecular basis for this. It is known that elevated expression of survival genes could confer resistance to apoptosis of tumor cells (27-29). Therefore, we checked the expression of the known anti-apoptosis genes $B C L 2$ and Survivin by real-time RT-PCR. We found that HepG2 cells exhibit significant higher levels of BCL2 (7-fold) and Survivin (2.5-fold) compared to HB cells (Fig. 3e), thus emphasizing that inhibition of apoptosis by overexpression of survival genes is one possible mechanism for the resistance of these cells against BA.

$B A$ inhibits known target genes of hedgehog signaling. Deregulation of hedgehog signaling plays a fundamental role in an increasing number of malignancies, including solid childhood tumors $(30,31)$. We recently described that overexpression of hedgehog target genes such as GLII and PTCH1 are frequently found in HB (25). Since HepT3 cells display an activated hedgehog signaling pathway (25), we wondered whether BA has any impact on the signaling cascade in these cells. Using real-time RT-PCR analysis for the known hedgehog target genes GLII, PTCHI and IGF2 (31), we found a significant reduction of mRNA levels for all three tested genes in HepT3 cells after BA treatment (Fig. 4). In contrast, the HCC cell line HepG2, which has already been reported to lack activation of the hedgehog signaling pathway (32), showed no relevant changes in target gene expression. These results suggest that BA is able to inhibit hedgehog signaling at least on the transcriptional level.

\section{Discussion}

The current therapy protocol for HB is based on systemic chemotherapy and surgery and strives for removal of the entire tumor, because cure without complete resection is 
a
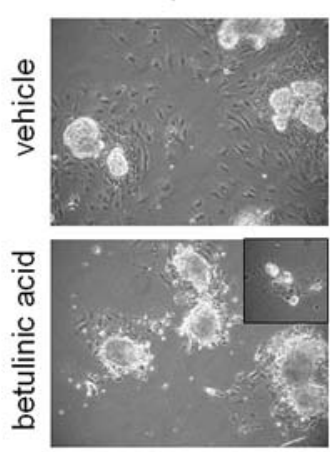

b

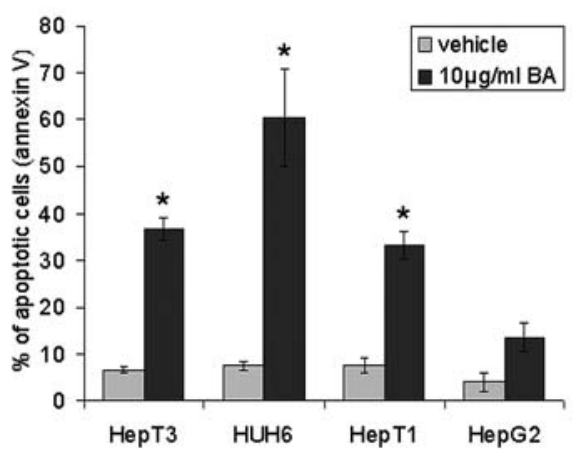

HepT1
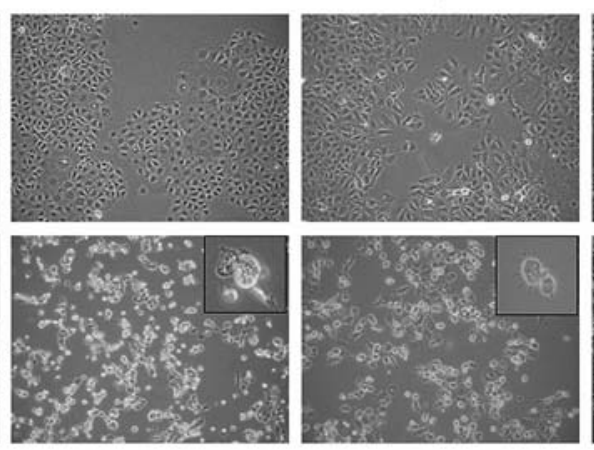

C

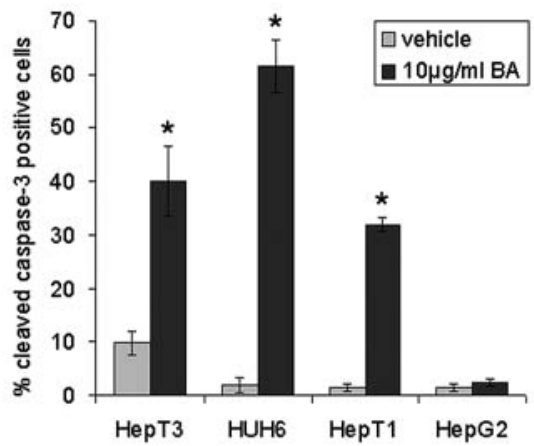

d

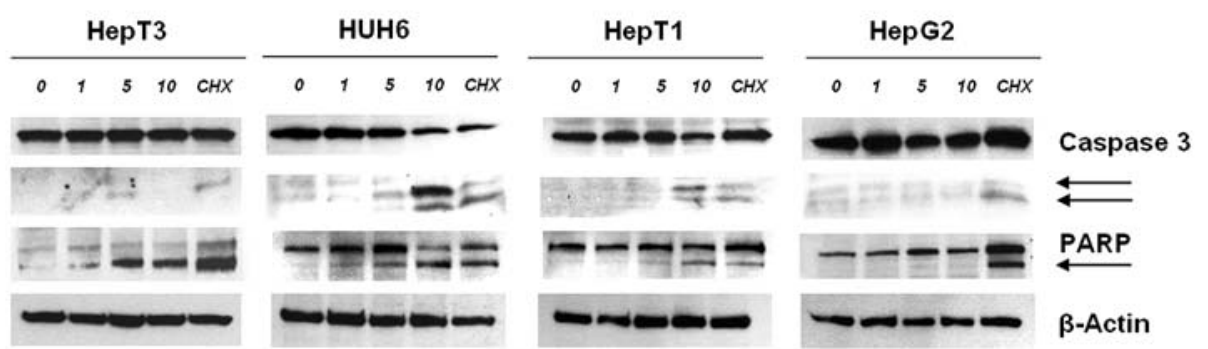

e
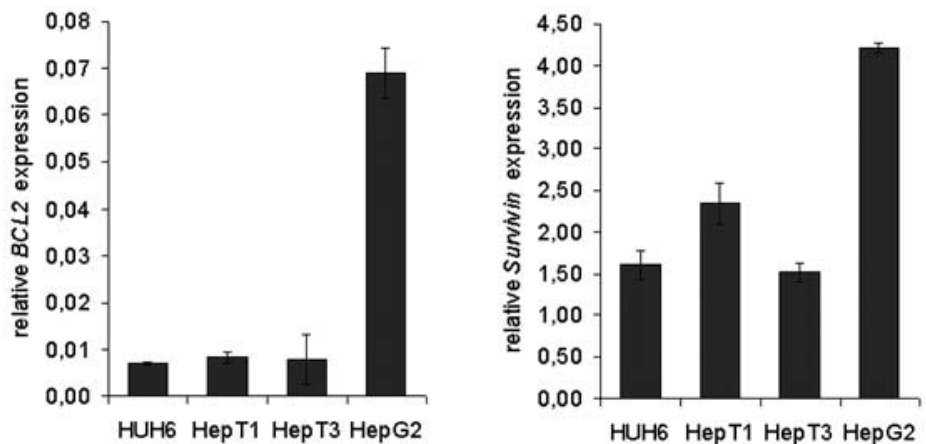

Figure 3. Apoptosis induction in BA-treated HB cell lines. (a) Morphology. HB cells (HepT3, HUH6 and HepT1) and a HCC cell line (HepG2) were treated for $24 \mathrm{~h}$ with or without $10 \mu \mathrm{g} / \mathrm{ml} \mathrm{BA}$. Typical morphological changes after apoptosis induction were observed in all three HB cell lines, but not in the HCC cell line. Insets show apoptotic cells at high magnification. (b) Annexin V staining. Cells were treated for $24 \mathrm{~h}$ with $10 \mu \mathrm{g} / \mathrm{ml} \mathrm{BA}$ or vehicle followed by apoptosis assay using Cy5-conjugated annexin $\mathrm{V}$ and calcein. Results are means \pm standard deviation of two experiments performed in duplicates and are expressed as percentages of early apoptotic cells (annexin V and calcein-positive). Statistical significant difference versus vehicle; ${ }^{*} \mathrm{P}<0.05$ (unpaired Student's t-test). (c) Activation of caspase 3. Apoptotic cells were counted under a fluorescence microscope after $48 \mathrm{~h}$ incubation with $10 \mu \mathrm{g} / \mathrm{ml} \mathrm{BA}$ using immunofluorescent detection of cleaved caspase 3 and nuclear counterstaining. Percentages of cleaved caspase 3-positive cells are depicted. Statistical significant difference versus vehicle; ${ }^{*} \mathrm{P}<0.05$ (unpaired Student's t-test). (d) Western Blot analysis. HB cells were treated for $24 \mathrm{~h}$ with $10 \mu \mathrm{g} / \mathrm{ml} \mathrm{BA}$ as indicated and expression of caspase 3, poly(ADP-ribose) polymerase (PARP), and B-actin was detected by Western blot analysis. Cleaved caspase 3 and PARP are indicated by arrows. Cycloheximide $(100 \mu \mathrm{g} / \mathrm{ml}$; CHX) was used as a positive control for apoptosis induction. Immunodetection of $\beta$-actin served as a standard control for equal protein loading. (e) Real-time RT-PCR. The mRNA expression of the anti-apoptotic genes BCL2 and Survivin was measured in HB and HCC cells by real-time RT-PCR in relation to the house-keeping gene $T B P$ as a calibrator. 

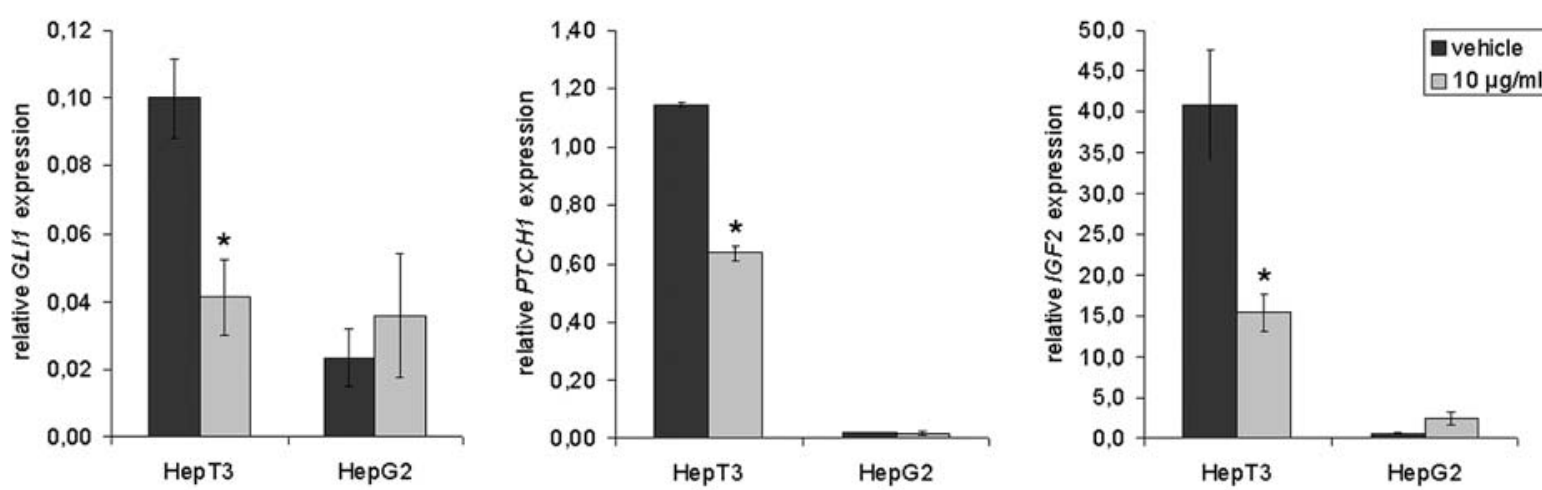

Figure 4. BA interferes with hedgehog signaling. Hedgehog-activated HepT3 and hedgehog-non-activated HepG2 cells were treated for $24 \mathrm{~h}$ with $10 \mu \mathrm{g} / \mathrm{ml}$ BA. GLI1, PTCH1 and IGF2 mRNA expression from untreated (black bars) and BA-treated (grey bars) cells was measured by real-time RT-PCR. TBP expression was used as a calibrator. Statistical significant difference versus vehicle; ${ }^{*} \mathrm{P}<0.05$ (unpaired Student's t-test).

extremely unusual (33). Preoperative debulking of the tumor using chemotherapy still constitutes a major challenge especially in HB patients with advanced disease (5). Thus, new strategies to target tumor cells are essential to improve patient outcome. In the present study, we provide clear evidence that BA could be used as a powerful anti-tumoral agent to effectively inhibit $\mathrm{HB}$ growth in vitro. We could furthermore demonstrate that BA strongly induces apoptosis in $\mathrm{HB}$ cells. Additionally, BA treatment led to a significant decrease in expression of the hedgehog target genes GLII, PTCH1 and IGF2 in the hedgehog-activated HB cell line HepT3. Together, these data indicate that BA might be a hopeful new agent for treating $\mathrm{HB}$, especially those with an activated hedgehog signaling pathway.

Activation of the PI3K/AKT pathway is a common feature of a variety of human cancers, especially those of early childhood $(11,34)$. Phosphorylation of the serine/threonine kinase AKT is known to trigger inactivation of proapoptotic factors, which in turn confers a survival advantage to tumor cells (12). Since our study clearly shows that AKT is activated in all HB cell lines under investigation independent of their histology, it is safe to predict that IGF2 overexpression, which is frequently found in $\mathrm{HB}(6,9)$, leads to an autocrine IGF2 regulatory circuit that constitutively drives HB growth. Based on this assumption it is intriguing that BA treatment is able to effectively inhibit growth and induce apoptosis in HB cells. Our data stand in line with studies on other childhood tumors such as medulloblastoma, neuroblastoma, glioblastoma and Ewing's sarcoma $(16,22,23)$. The finding that the level of proteolytically cleaved caspase 3 dramatically increased in $\mathrm{HB}$ cells upon BA treatment suggests that BA induces apoptosis through the intrinsic mitochondrial pathway. This is consistent with previous reports convincingly demonstrating that BA-induced apoptosis is mediated by acting directly on the mitochondria $(17,18)$. Thus, the mode of BA action seems to be the same in a variety of cancers. This is particularly intriguing in view of treating tumors such as HB in which upstream components of apoptosis-inducing signaling pathways are interrupted. In view of a clinical setting one has to realize that all studies conducted so far used a comparable BA concentration of 5-20 $\mu \mathrm{g} / \mathrm{ml}$. Most importantly, these BA levels could be reached in the serum of mice after intraperitoneal administration and were tolerated without toxic side-effects (35). In this context it is worth mentioning that BA treatment in our study had a selective effect on tumor cells leaving normal fibroblasts grossly viable, which corroborates previous studies using proliferating normal lymphocytes and mouse fibroblasts $(15,19)$. Taken together, our successful strategy of blocking IGF2-mediated cancer cell survival by inducing apoptosis might display a rationale for the future treatment of HB. Since it has been reported that BA could sensitize cancer cells for anticancer drugs (36), BA may be used in combination to established treatment regimens in future therapeutic approaches.

However, the inability of the HCC cell line HepG2 to undergo apoptosis upon BA treatment also point to some limitation of this agent. We found at least one explanation for the resistance of these tumor cells, namely the upregulation of the anti-apoptosis genes BCL2 and Survivin. This is in accordance with previous studies showing that $B C L 2$ as well as Survivin could inhibit the intrinsic mitochondrial apoptosis pathway $(37,38)$. To circumvent the insensitivity to chemotherapeutic drugs or induction of apoptosis in pediatric liver cancer cells several attempts have already been made to modulate the intrinsic expression of BCL2 and Survivin, showing the importance of these two anti-apoptotic proteins in inhibiting apoptosis (39-41). Altogether these data suggest that decreasing the expression levels of survival genes combined with conventional chemotherapeutical treatment might be a promising approach to overcome the prevalent resistance of tumors.

An additional intriguing result of the present study is that BA has an impact on the hedgehog signaling pathway. Deregulation of hedgehog signaling plays a fundamental role in an increasing number of malignancies $(30,31)$, and we have recently added HB to the list (25). Here, we report on the transcriptional repression of the known hedgehog target genes GLII , PTCHI and IGF2 in hedgehog-activated HepT3 cells, while HepG2 known to lack activation of the hedgehog signaling pathway (32) showed no reduction in target gene expression. These results are in line with a recent study of Arai et al (42), which suggests that BA is able to inhibit hedgehog signaling on the level of the transcription factor GLI1. GLI-dependent luciferase reporter assays were used for screening a natural resource library for hedgehog- 
inhibiting compounds. Among others BA had the strongest inhibitory effect on GLI1-mediated transcriptional activity. Selective targeting of the hedgehog pathway is nowadays heavily discussed to add therapeutic benefit to current cancer treatments (reviewed in ref. 43). This hope was fueled by the first promising preclinical studies on digestive tract tumors, pancreatic and small-cell lung cancer as well as medulloblastoma, in which blocking the hedgehog pathway consistently showed a dramatic retardation of tumor growth in vivo (reviewed in refs. 30,31). Clinical phase I and II studies using hedgehog inhibitors for advanced and/or metastatic solid tumors are currently underway.

In summary, our results convincingly show that BA treatment causes extensive apoptosis and inhibition of hedgehog signaling in $\mathrm{HB}$. Since BA obviously is effective in a growing number of cancers the use of BA or more potent derivatives might be a promising approach for clinical applications in the treatment of hedgehog-dependent cancers, including pediatric liver tumors.

\section{Acknowledgements}

This work was supported by grants of the Horst Müggenburg foundation, Hamburg (to R.K.) and the Projekt Omnibus foundation, Munich (to D.v.S. and R.K.).

\section{References}

1. Mann JR, Kasthuri N, Raafat F, Pincott JR, Parkes SE, Muir KR, Ingram LC and Cameron AH: Malignant hepatic tumours in children: incidence, clinical features and aetiology. Paediatr Perinat Epidemiol 4: 276-289, 1990.

2. Litten JB and Tomlinson GE: Liver tumors in children. Oncologist 13: 812-820, 2008.

3. Weinberg AG and Finegold MJ: Primary hepatic tumors of childhood. Hum Pathol 14: 512-537, 1983.

4. Perilongo G, Shafford E and Plaschkes J: SIOPEL trials using preoperative chemotherapy in hepatoblastoma. Lancet Oncol 1: 94-100, 2000.

5. Von Schweinitz D: Management of liver tumors in childhood. Semin Pediatr Surg 15: 17-24, 2006.

6. Hartmann W, Waha A, Koch A, Goodyer CG, Albrecht S, von Schweinitz D and Pietsch T: p57(KIP2) is not mutated in hepatoblastoma but shows increased transcriptional activity in a comparative analysis of the three imprinted genes p57(KIP2), IGF2, and H19. Am J Pathol 157: 1393-1403, 2000

7. Honda S, Arai Y, Haruta M, Sasaki F, Ohira M, Yamaoka H, Horie H, Nakagawara A, Hiyama E, Todo S and Kaneko Y: Loss of imprinting of IGF2 correlates with hypermethylation of the $\mathrm{H} 19$ differentially methylated region in hepatoblastoma. $\mathrm{Br} \mathrm{J}$ Cancer 99: 1891-1899, 2008.

8. Rainier S, Dobry CJ and Feinberg AP: Loss of imprinting in hepatoblastoma. Cancer Res 55: 1836-1838, 1995.

9. Gray SG, Eriksson T, Ekstrom C, Holm S, von Schweinitz D, Kogner P, Sandstedt B, Pietsch T and Ekstrom TJ: Altered expression of members of the IGF-axis in hepatoblastomas. Br J Cancer 82: 1561-1567, 2000.

10. Pollak M: Insulin and insulin-like growth factor signalling in neoplasia. Nat Rev Cancer 8: 915-928, 2008.

11. Yuan TL and Cantley LC: PI3K pathway alterations in cancer: variations on a theme. Oncogene 27: 5497-5510, 2008.

12. Manning BD and Cantley LC: AKT/PKB signaling: navigating downstream. Cell 129: 1261-1274, 2007.

13. Pisha E, Chai H, Lee IS, Chagwedera TE, Farnsworth NR, Cordell GA, Beecher CW, Fong HH, Kinghorn AD, Brown DM, et al: Discovery of betulinic acid as a selective inhibitor of human melanoma that functions by induction of apoptosis. Nat Med 1: 1046-1051, 1995.

14. Alakurtti S, Makela T, Koskimies S and Yli-Kauhaluoma J: Pharmacological properties of the ubiquitous natural product betulin. Eur J Pharm Sci 29: 1-13, 2006.
15. Zuco V, Supino R, Righetti SC, Cleris L, Marchesi E, Gambacorti-Passerini C and Formelli F: Selective cytotoxicity of betulinic acid on tumor cell lines, but not on normal cells. Cancer Lett 175: 17-25, 2002.

16. Fulda S and Debatin KM: Betulinic acid induces apoptosis through a direct effect on mitochondria in neuroectodermal tumors. Med Pediatr Oncol 35: 616-618, 2000.

17. Fulda S, Friesen C, Los M, Scaffidi C, Mier W, Benedict M, Nunez G, Krammer PH, Peter ME and Debatin KM: Betulinic acid triggers CD95 (APO-1/Fas)- and p53-independent apoptosis via activation of caspases in neuroectodermal tumors. Cancer Res 57: 4956-4964, 1997.

18. Fulda S, Scaffidi C, Susin SA, Krammer PH, Kroemer G, Peter ME and Debatin KM: Activation of mitochondria and release of mitochondrial apoptogenic factors by betulinic acid. J Biol Chem 273: 33942-33948, 1998.

19. Sarek J, Klinot J, Dzubak P, Klinotova E, Noskova V, Krecek V, Korinkova G, Thomson JO, Janost'akova A, Wang S, Parsons S, Fischer PM, Zhelev NZ and Hajduch M: New lupane derived compounds with pro-apoptotic activity in cancer cells: synthesis and structure-activity relationships. J Med Chem 46: 5402-5415, 2003.

20. Hartmann W, Digon-Sontgerath B, Koch A, Waha A, Endl E, Dani I, Denkhaus D, Goodyer CG, Sorensen N, Wiestler OD and Pietsch T: Phosphatidylinositol 3'-kinase/AKT signaling is activated in medulloblastoma cell proliferation and is associated with reduced expression of PTEN. Clin Cancer Res 12: 3019-3027, 2006.

21. Zumkeller W and Schwab M: Insulin-like growth factor system in neuroblastoma tumorigenesis and apoptosis: potential diagnostic and therapeutic perspectives. Horm Metab Res 31: 138-141, 1999.

22. Fulda S, Jeremias I, Steiner HH, Pietsch T and Debatin KM: Betulinic acid: a new cytotoxic agent against malignant braintumor cells. Int J Cancer 82: 435-441, 1999.

23. Schmidt ML, Kuzmanoff KL, Ling-Indeck L and Pezzuto JM: Betulinic acid induces apoptosis in human neuroblastoma cell lines. Eur J Cancer 33: 2007-2010, 1997.

24. Pietsch T, Fonatsch C, Albrecht S, Maschek H, Wolf HK and von Schweinitz D: Characterization of the continuous cell line HepT1 derived from a human hepatoblastoma. Lab Invest 74 : 809-818, 1996.

25. Eichenmüller M, Gruner I, Hagl B, Häberle B, Müller-Höcker J, von Schweinitz D and Kappler R: Blocking the hedgehog pathway inhibits hepatoblastoma growth. Hepatology 49: 482-490, 2009.

26. Pfaffl MW: A new mathematical model for relative quantification in real-time RT-PCR. Nucleic Acids Res 29: e45, 2001.

27. Cory S, Huang DC and Adams JM: The Bcl-2 family: roles in cell survival and oncogenesis. Oncogene 22: 8590-8607, 2003.

28. Li F, Ambrosini G, Chu EY, Plescia J, Tognin S, Marchisio PC and Altieri DC: Control of apoptosis and mitotic spindle checkpoint by survivin. Nature 396: 580-584, 1998.

29. Niedzielska G and Kocki J: Evaluation of bcl-2 gene expression in papilloma of larynx in children. Int J Pediatr Otorhinolaryngol 53: 25-29, 2000.

30. Evangelista M, Tian $\mathrm{H}$ and De Sauvage FJ: The hedgehog signaling pathway in cancer. Clin Cancer Res 12: 5924-5928, 2006.

31. Ruiz i Altaba A, Sanchez P and Dahmane N: Gli and hedgehog in cancer: tumours, embryos and stem cells. Nat Rev Cancer 2: 361-372, 2002.

32. Huang S, He J, Zhang X, Bian Y, Yang L, Xie G, Zhang K, Tang W, Stelter AA, Wang Q, Zhang $\mathrm{H}$ and Xie J: Activation of the hedgehog pathway in human hepatocellular carcinomas. Carcinogenesis 27: 1334-1340, 2006.

33. von Schweinitz D, Hecker H, Harms D, Bode U, Weinel P, Burger D, Erttmann R and Mildenberger H: Complete resection before development of drug resistance is essential for survival from advanced hepatoblastoma-a report from the German Cooperative Pediatric Liver Tumor Study HB-89. J Pediatr Surg 30: 845-852, 1995.

34. Scotting PJ, Walker DA and Perilongo G: Childhood solid tumours: a developmental disorder. Nat Rev Cancer 5: 481-488, 2005.

35. Udeani GO, Zhao GM, Geun Shin Y, Cooke BP, Graham J, Beecher CW, Kinghorn AD and Pezzuto JM: Pharmacokinetics and tissue distribution of betulinic acid in CD-1 mice. Biopharm Drug Dispos 20: 379-383, 1999.

36. Fulda S and Debatin KM: Sensitization for anticancer druginduced apoptosis by betulinic Acid. Neoplasia 7: 162-170, 2005. 
37. Certo M, Del Gaizo Moore V, Nishino M, Wei G, Korsmeyer S, Armstrong SA and Letai A: Mitochondria primed by death signals determine cellular addiction to antiapoptotic BCL-2 family members. Cancer Cell 9: 351-365, 2006.

38. Dohi T, Beltrami E, Wall NR, Plescia J and Altieri DC: Mitochondrial survivin inhibits apoptosis and promotes tumorigenesis. J Clin Invest 114: 1117-1127, 2004.

39. Li D, Chen X and Zhang W: The inhibition of apoptosis of hepatoma cells induced by $\mathrm{HBx}$ is mediated by up-regulation of survivin expression. J Huazhong Univ Sci Technolog Med Sci 23: 383-386, 2003

40. Warmann SW, Frank H, Heitmann H, Ruck P, Herberts T, Seitz G and Fuchs J: Bcl-2 gene silencing in pediatric epithelial liver tumors. J Surg Res 144: 43-48, 2008.
41. Zhang W, Chen X and Qiu F: An antisense plasmid targeting survivin expression induces apoptosis and sensitizes hepatocarcinoma cells to chemotherapy. J Huazhong Univ Sci Technolog Med Sci 23: 387-391, 2003.

42. Arai MA, Tateno C, Hosoya T, Koyano T, Kowithayakorn T and Ishibashi M: Hedgehog/GLI-mediated transcriptional inhibitors from Zizyphus cambodiana. Bioorg Med Chem 16: 9420-9424, 2008

43. Rubin LL and De Sauvage FJ: Targeting the Hedgehog pathway in cancer. Nat Rev Drug Discov 5: 1026-1033, 2006. 